\title{
The Most Common Injuries among Jordanian Wheelchair Athletes
}

\author{
Rami M. Hammad ${ }^{\text {* }}$, Saleh M. Hammad ${ }^{2}$, Majed F. Mujalli ${ }^{3}$ \\ University of Jordan, Jordan
}

*Corresponding Author: Rami M. Hammad, University of Jordan, Jordan

\begin{abstract}
The purpose of this study is to determine the most common injuries occurring amongst throwing sports wheelchair athletes. The examined group consists of individual athletes on wheelchairs. These selected athletes suffer from spinal cord injuries. Sports Research on this group of athletes is regionally marginalized, including in Jordan. Therefore, this study is one of the first ones to evaluate training practices and treatments after injuries concerning a group of athletes in a systematic way in Jordan. By using a questionnaire, a data of 55 athletes was collected and analyzed through the Chi square test. The criteria that were applied for the analysis and categorization of the data were cause of injury, time of injury and type of treatment used. The results further indicated that most of the injuries occurred during training in the preparation period for competitions where the shoulder joints are intensively used while those are the most vulnerable areas $(46.6 \%) . I t$ can be assumed that wheelchair athletes do not receive the same quality of coaching as other athletes due to less public interest and funding. As for the treatment methods used, physiotherapy is practiced more frequently than other methods (86.3\% of the total number of injuries) with barely any differences in treatment compared to non-disabled athletes. With regard to the results, the most important recommendations for this specific group of athletes are to strictly follow training programs and to adhere to the principles of complete warm-up to reduce the occurrence of injuries.
\end{abstract}

Keywords: Wheelchair, Jordanian, Injuries, Javelin Throw, Discus Throw, Shot-Put.

\section{INTRODUCTION}

The aim of sport is to spread peace and cooperation amongst human beings. Sport is not exclusive, as it allows everyone to exercise physical activities, in a recreational or competitive manner, whether the person is young or old, male or female. Physical activities and practices sports have a positive impact on the individual's physiological abilities, psychological and social aspects. Nowadays, many athletes and trainers are focused on achieving high results and winning sports medals, as a way to gain money, recognition and fame and find fulfillment in their life, to investigate the professionalism within ethical principles. Over the past several centuries, people with special needs have suffered from exclusion and negligence. They have been regarded as lacking abilities and they have been treated as "thirdclass" citizens by governmental policies. Particularly, during the centuries Before Christ people with special needs were killed. Over the centuries, this group finally started to enjoy the right to live and to practice sports in a more accessible way, enabling them to practice sports activities and to win medals at both regional and global levels. (Corbett, \& Barton., 2018)

Individual sports are more personal and skill-based than collective sports in which the team cooperates for the achievement of sports results. Moreover, they do not provide the same turnout, participation, attention, follow-up and encouragement of collective sports. Individual games include several complex skills, and they are characterized by a high effort exerted by the player in training and competition. This effort is accompanied by a high probability of sports injuries because of the pressure on various body organs, in particular the motor system, represented by multiple body systems; bones, joints, muscles, and tendons. The efforts vary from one sport game to another, depending on the type of skills performed. (Chaitow, L., \&DeLany, J., 2011)

Physical activity during adolescence provides multidimensional health benefits, but it is worth highlighting that the risk of sports injuries increases along with the volume, intensity and competitiveness of sports activities. Youth team sports carry a higher injury risk than individual 
sports. Earlier studies have focused only on acute or repetitive injuries on both females and males or on a specific injury, such as anterior cruciate ligament rupture. (Walden et al., 2011)

There are scattered studies on athletes, covering various different sports and different types of injuries. For instance, the occurrence and risk factors of different types of unintentional injuries among Finnish adolescents have previously been studied. Injuries of sports club members have been previously studied, but far less focus on special needs athletes. Furthermore, the occurrence of repetitive injuries has been studied less than acute injuries. The American Medical Society for Sports Medicine made a position statement concerning repetitive injuries and burnout, which are common problems in sports. (DiFiori et al., 2014)

According to Leppanen et al. (2017), there are multiple causes for sports injuries and, depending on the sport, some parts of the athlete's body is more likely to be injured, and the number of athletes getting injured is increasing. Drawing from this finding, we decided to carry out the present research, under the title "The Most Common Injuries Among Jordanian Wheelchair Athletes".

\section{Participants}

Fifty-Five athletes in wheelchair of both genders (age: $31.1 \pm 9.72$; training time: $2.11 \pm 0.77$; training days a week: $4.00 \pm 1.75$ ) from the Jordanian Paralympics Committee participated in the study. Participants were players of Throwing Sports namely Javelin Throw, Discus Throw and Shot-Put that possessed similar backgrounds, athletic abilities and sportive experiences. The researchers used the descriptive method approach to suit the nature and objectives of the study.

\section{DATA COLLECTION AND ANALYSIS}

The researchers have been approved by an ethics review board, and they have adopted a questionnaire produced by Mujalli, m., 2007that has been modified in order to collect the data needed. This questionnaire requested the athletes to explain their injuries, the training phase in which they were injured (preparation, competition or resting time) and the treatment and rehabilitation necessary to be in a good condition and to restart training. Since the original questionnaire enquires upon the entire body, we have chosen to adjust it to our sample by avoiding questions regarding the lower part of the body, as it is assumed that the athletes do not use the lower part of their body in their sport practice. Thus, we have modified and investigated exclusively the upper part of the body, from the head to the hips. The data has been analyzed through Frequencies, Percentages and Chi Square test.

\section{Results}

The results obtained fulfill the purpose of the present research which aims at detecting the most common injuries for athletes in wheelchair doing individual sports. The findings are as follows:

Table1: Number, percentage of types of injuries for Jordanian Wheelchairs Athletes in individual sports

\begin{tabular}{|l|l|l|}
\hline \multicolumn{1}{|c|}{ Types of injuries } & \multicolumn{1}{c|}{ Number of injuries } & \% of injuries \\
\hline Ruptured or tear tendons & 14 & 20.5 \\
\hline Contractions & 10 & 14.7 \\
\hline Bone Bruises & 9 & 13.2 \\
\hline Tearing muscles & 8 & 11.7 \\
\hline Ruptured or tear ligaments & 7 & 10.2 \\
\hline Fractions & 6 & 8.8 \\
\hline Muscle Bruises & 6 & 8.8 \\
\hline Wounds and scratches & 3 & 4.4 \\
\hline dislocation & 3 & 4.4 \\
\hline Sprain & 2 & 2.9 \\
\hline Nerve Bruises & 0 & 0.0 \\
\hline Total & 60 & 100 \\
\hline
\end{tabular}

Table (1) shows that the most common types of injuries among Jordanian Wheelchair Athletes are "tear tendons" as it represents $20.5 \%$, followed by Contractions injury (14.7\%), and Bone Bruises(13.2\%), then Tearing muscles (11.7\%). It also notes that less types of injuries suffered by individual Wheelchair Athletes is Abstract in Nerve Bruises that have a percentage of $0.0 \%$, followed by a Sprain injury $(2.9 \%)$, then Wounds and scratches and dislocation $(4.4 \%)$. The total number of casualties among members of the study sample (60) were distributed among different injury proportions shown in TableNo.2. 
The Most Common Injuries among Jordanian Wheelchair Athletes

Table2: Number, percentage of injuries for Jordanian Wheelchairs Athletes in individual sports

\begin{tabular}{|l|l|l|}
\hline \multicolumn{1}{|c|}{ Injuries locations } & \multicolumn{1}{c|}{ Number of injuries } & \multicolumn{1}{c|}{ \% of injuries } \\
\hline Head & 0 & 0.0 \\
\hline Neck & 0 & 0.0 \\
\hline Shoulder joint & 28 & 46.6 \\
\hline Collarbone & 1 & 1.6 \\
\hline Upper arm & 3 & 5.0 \\
\hline Elbow joint & 9 & 15.0 \\
\hline Forearm & 4 & 6.6 \\
\hline Wrist joint & 7 & 11.6 \\
\hline hands & 2 & 3.3 \\
\hline Fingers & 5 & 8.3 \\
\hline Sternum & 0 & 0.0 \\
\hline Ribs & 1 & 1.6 \\
\hline Backbones & 0 & 0.0 \\
\hline Abdomen & 0 & 0.0 \\
\hline Hip joint & 0 & 0.0 \\
\hline Total & 60 & 100 \\
\hline
\end{tabular}

Table (2) shows that the part of the body that is the most vulnerable to infection is the joint of the shoulder (46.6\%), followed by the elbow joint (15.0\%) and the wrist joint (11.6\%). Body parts that are less susceptible to injuries are hip joint, abdomen, backbones, the sternum, neck and head $(0.0 \%)$ while ribs and collarbone are slightly more frequent (1.6\%).

Table3: Number, percentage of causes leading to injuries for Jordanian Wheelchairs Athletes in individual sports

\begin{tabular}{|c|c|c|c|}
\hline No. & Causes of injury & Number of injuries & $\%$ of injuries \\
\hline 1 & Lack of good warm-up & 25 & 41.6 \\
\hline 2 & Over training & 8 & 13.3 \\
\hline 3 & Lack of attention, haste & 12 & 20.0 \\
\hline 4 & The court ground is so bad & 0 & 0.0 \\
\hline 5 & Technic preparation is bad & 2 & 3.3 \\
\hline 6 & Continue training when the injury occurs & 4 & 6.6 \\
\hline 7 & Inefficient Sport wear & 0 & 0.0 \\
\hline 8 & Coach and athlete did not restrict to a correct training program & 0 & 0.0 \\
\hline 9 & Inability of used sports equipment & 0 & 0.0 \\
\hline 10 & Lack of guidance and awareness of coach & 3 & 4.9 \\
\hline 11 & Poor selection of exercise to the training unit & 0 & 0.0 \\
\hline 12 & Not following safety and security rules & 0 & 0.0 \\
\hline 13 & Bad selection of training for the muscle group & 0 & 0.0 \\
\hline 14 & The coach does not guide the player during the training & 0 & 0.0 \\
\hline 15 & No sufficient rest between exercise and after & 0 & 0.0 \\
\hline 16 & Allow the player to return to training before full recovery & 1 & 1.6 \\
\hline 17 & Do not relax well after exercise & 1 & 1.6 \\
\hline 18 & Lack of adequate supplies of training and competition tools & 1 & 1.6 \\
\hline 19 & Non-use of sports rehabilitation facilities (massage / sauna) & 2 & 3.3 \\
\hline 20 & Improper stop for training and games & 0 & 0.0 \\
\hline 21 & Do not perform regular medical examinations & 0 & 0.0 \\
\hline 22 & Non-adherence to a diet program & 0 & 0.0 \\
\hline 23 & $\begin{array}{l}\text { Not to take into consideration the individual differences between } \\
\text { the players and their training within their physical potential }\end{array}$ & 1 & 1.6 \\
\hline 24 & Poor psychological preparation & 0 & 0.0 \\
\hline 25 & $\begin{array}{l}\text { Lack of knowledge and knowledge of the science of sports } \\
\text { injuries and their causes and ways of prevention }\end{array}$ & 0 & 0.0 \\
\hline 26 & $\begin{array}{l}\text { Lack of precision and detail in choosing the appropriate sport } \\
\text { type }\end{array}$ & 0 & 0.0 \\
\hline 27 & Non-gradual increase in weight load & 0 & 0.0 \\
\hline \multirow[t]{2}{*}{28} & other reasons & 0 & 0.0 \\
\hline & Total & 60 & 100.0 \\
\hline
\end{tabular}

Table (3) shows the percentage of frequencies and percentages of the causes of the injuries of the individual sport of Wheelchairs Athletes and the review of percentage values. The most important 
reasons are "lack of good warm-up" (41.6\%), followed by "lack of good behavior for athletes i.e. the lack of attention and haste $(20.0 \%)$ and over-training" (13.3\%). It is worth noticing that many of the reasons listed in the table did not lead to any injuries to these individuals in the sample.

Table4: Number, percentage of injuries and the value of Chi square of the treatment used by the Jordanian Wheelchairs Athletes in individual sports

\begin{tabular}{|c|c|c|c|c|}
\hline Treatment type & Number of injuries & \%of injuries & ${ }^{2} \chi$ & prob \\
\hline physiotherapy & 52 & 86.3 & 78.40 & \multirow[t]{3}{*}{0.00} \\
\hline medicine & 8 & 13.2 & & \\
\hline surgical & 0 & 0.0 & & \\
\hline Total & 60 & 100.0 & & \\
\hline
\end{tabular}

The table shows that the most common treatment methods for these athletes were physical treatment $(86.3 \%)$ followed by the use of drugs $(13.2 \%)$ while the lowest treatment methods used were surgical treatment $(0.0 \%)$. The value of the Chi Square (78.4) indicates that there are statistically significant differences between the methods of treatment of injuries suffered by the athletes.

Table5: Number, percentage of injuries and Chi square value of the time when Jordanian Wheelchairs Athletes got injured

\begin{tabular}{|l|l|l|l|l|}
\hline \multicolumn{1}{|c|}{ Treatment type } & Number of injuries & \multicolumn{1}{c|}{ \%of injuries } & $2^{2} \chi$ & prob \\
\hline Preparation time & 56 & 92.9 & 97.0 & \\
\hline Competition time & 2 & 3.3 & & \\
\hline Resting time & 2 & 3.3 & & \\
\hline Total & 60 & 100.0 & & \\
\hline
\end{tabular}

Table (5)shows that the most common time span in which the injuries occurred was the time of preparation $(92.9 \%)$, followed by the competition $(3.3 \%)$. The injuries during the resting time occurred only in 3.3\% of cases. The value of the Chi Square (97.0) indicated that there were statistical differences between the time of injury because the value of the significance level (0.0) was less than 0.05 .

\section{DISCUSSION}

According to Weldon \& Richardson (2001), wheelchair athletes of Javelin Throw and Shot-Put tend to use wrong techniques or overuse their shoulders when throwing the shot or the spear, causing injuries to this part of the body. The injuries of the shoulder joint are due to the lack of a good warmup before exercise, overtraining and lack of athletes' attention, confirming the result obtained by Andersson et al., (2017).In the researchers' view, a major issue contributing to injuries during the warm-up time is the lack of adequate education of the trainers and lack of experience in assessing whether the athletes need to warm-up more or take breaks, those trainers are the people who build the training program for the training season and control the training intensity while they lack knowledge. All of these factors lead to injury. Moreover, the researchers believe that the way athletes sit and curb to the chair during their sport activity plays a fundamental role in the occurrence of injuries, whether they are marathon runners or disk, shot and spear players. Moreover, it is highlighted that a strong movement might reflect directly on the injured tendons. The researchers believe that the reason for the spread of these injuries, like in any other sport, relies on the power of the body and the anatomical form of the shoulder joint and quality of the kinematic performance.

It is known that the muscles are the main support for the body skeleton. Tendons are the main point of connection between the muscles and the bones. Therefore, when the athlete starts the training without doing a proper warm-up, the tendons will be the weak point in comparison with the strong bones and the unready muscles, so the tendons around the shoulder joint were the most prevalent injury (20.5\%), aligning with the results of Krajnik et al., (2010) and Bonza et al., (2009). Regarding the prevalence physiotherapeutic treatment, an explanation could derive from the nature of the muscle injured. The researchers believe that, since the tendons around the shoulder joint are in a small size, a tear to them will only cause a tolerable pain to the athlete. Therefore, he or she will be less likely to go to hospital. Instead, they will only seek treatment from a Paralympic physiotherapist.

\section{Conclusions}

From the data analysis, it emerged that there is only a main cause leading to injuries amongst wheelchair athletes, i.e. the lack of good warm-up. The most common injury is the tear of the tendons of the small muscles around the shoulder joint. 
We recommend the Jordanian Paralympic Committee to pay attention to the coaches' work and if it is not satisfying, to provide the coaches with courses so that they can get better.

\section{REFERENCES}

[1] Andersson, S. H., Bahr, R., Clarsen, B., \& Myklebust, G. (2017). Preventing overuse shoulder injuries among throwing athletes: a cluster-randomised controlled trial in 660 elite handball players. Br J Sports Med, 51(14), 1073-1080.

[2] Bonza, J. E., Fields, S. K., Yard, E. E., \& Dawn Comstock, R. (2009). Shoulder injuries among United States high school athletes during the 2005-2006 and 2006-2007 school years. Journal of athletic training, 44(1), 76-83.

[3] Chaitow, L., \&DeLany, J. (2011). Clinical Application of Neuromuscular Techniques, Volume 2 E-Book: The Lower Body. Elsevier Health Sciences.

[4] Corbett, J., \& Barton, L. (2018). A struggle for choice: Students with special needs in transition to adulthood. Routledge.

[5] DiFiori, J. P., Benjamin, H. J., Brenner, J. S., Gregory, A., Jayanthi, N., Landry, G. L., \& Luke, A. (2014). Overuse injuries and burnout in youth sports: a position statement from the American Medical Society for Sports Medicine. Br J Sports Med, 48(4), 287-288.

[6] Krajnik, S., Fogarty, K. J., Yard, E. E., \& Comstock, R. D. (2010). Shoulder injuries in US high school baseball and softball athletes, 2005-2008. Pediatrics, 125(3), 497.

[7] Mari Leppanen, Kati Pasanen, PekkaKannus, TommiVasankari., (2017). Epidemiology of overuse injuries in Youth Team sports: A 3-year Prospective Study, International Journal of sports medicine.

[8] Mujalli, m., (2007). Sports Injuries by Practitioners of Sports Activities in Fitness Centers in Jordan: Educational Sciences. 2007, Vol. 34 Issue 2, p200-210. 11p.

[9] Waldén, M., Hägglund, M., Werner, J., \&Ekstrand, J. (2011). The epidemiology of anterior cruciate ligament injury in football (soccer): a review of the literature from a gender-related perspective. Knee surgery, sports traumatology, arthroscopy, 19(1), 3-10.

[10] Weldon III, E. J., \& Richardson, A. B. (2001). Upper extremity overuse injuries in swimming: a discussion of swimmer's shoulder. Clinics in sports medicine, 20(3), 423-438.

\section{AUTHORS' BIOGRAPHY}

Rami Hammad has completed his Bachelor of Science at the University of Jordan in 2017 and he completed post graduate in 2019, he is a Professor Assistant in Human Exercise Physiology at University of Jordan/ School of Physical Education, and he has Published Many Articles in Sports Sciences, His research interest is in human exercise physiology and sport injuries.

Citation: Rami M. Hammad, et.al. "The Most Common Injuries among Jordanian Wheelchair Athletes". International Journal of Humanities Social Sciences and Education (IJHSSE), vol. 6, no.11, 2019, pp. 20-24. doi: http://dx.doi.org/10.20431/2349-0381.0611003.

Copyright: () 2019 Authors. This is an open-access article distributed under the terms of the Creative Commons Attribution License, which permits unrestricted use, distribution, and reproduction in any medium, provided the original author and source are credited. 